\title{
REMARKS ON A PAPER BY S. TROTT
}

\author{
W. O.J. Moser \\ (received July 25, 1963)
}

There are several statements in [3] which require clarification.

Theorem $1\left[3\right.$, p. 246] states that $U_{3}=U_{2} U_{4} U_{2}^{-1} U_{4} U_{2} U_{4}$. In fact this is (essentially) the relation $O=P U P U^{-1} P U$ given in $[1$, p. $91,(7.35)]$. To see this we note that $O=U_{3}, P=U_{4}$, $U=U_{4} U_{2} U_{4}$ (as explained in $\left[1\right.$, p. 88]); since $U_{4}^{2}=E$,

$$
\begin{aligned}
\mathrm{U}_{3}=\mathrm{O}=\mathrm{PUPU} \mathrm{U}^{-1} \mathrm{PU} & =\mathrm{U}_{4} \cdot \mathrm{U}_{4} \mathrm{U}_{2} \mathrm{U}_{4} \cdot \mathrm{U}_{4} \cdot \mathrm{U}_{4} \mathrm{U}_{2}^{-1} \mathrm{U}_{4} \cdot \mathrm{U}_{4} \cdot \mathrm{U}_{4} \mathrm{U}_{2} \mathrm{U}_{4} \\
& =\mathrm{U}_{2} \mathrm{U}_{4} \mathrm{U}_{2}^{-1} \mathrm{U}_{4} \mathrm{U}_{2} \mathrm{U}_{4} .
\end{aligned}
$$

In [3, p. 245] there is the statement: "It has been shown by D. Beldin (Thesis, Reed College, 1957) that $M_{n}$ is a 2-generator group."

There is the implication that this had not been established earlier. In fact, B. Neumann [2, pp. 375-378] showed that $M_{n}$ is generated by

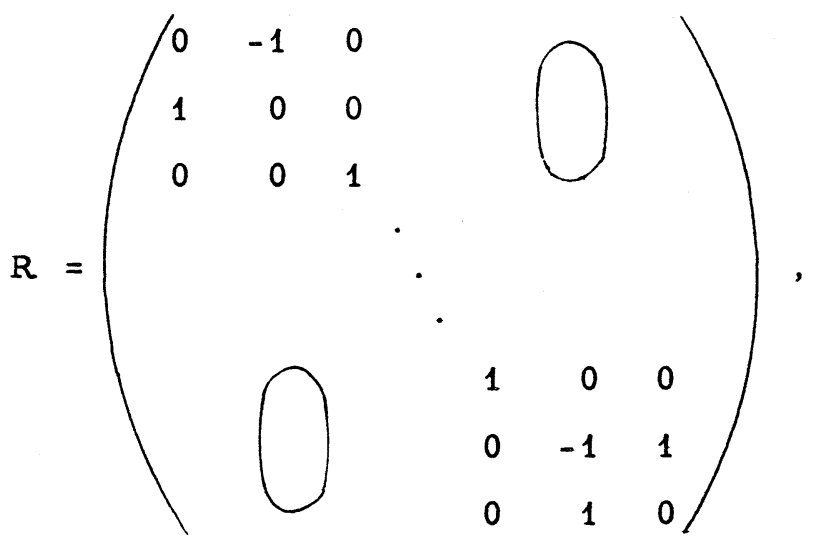

Canad. Math. Bull. vol. 7, no. 1, January 1964 


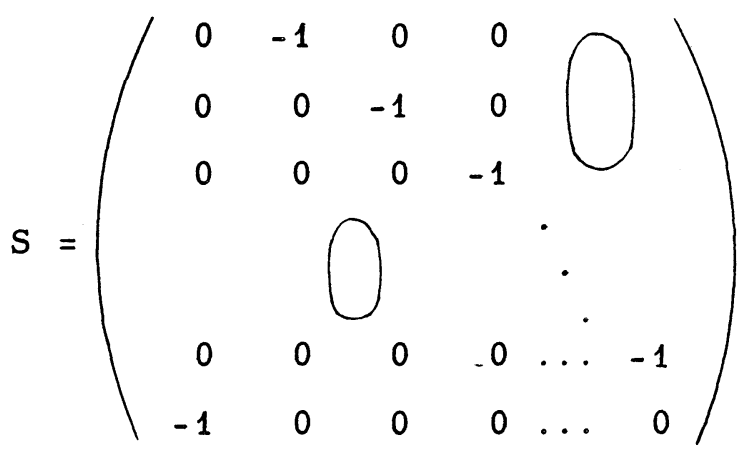

when $n$ is odd, $n>3$; and $M_{n}$ is generated by $R$ and $Q=-S$ when $\mathrm{n}$ is even, $\mathrm{n}>3$. Trott's generators

$$
\begin{aligned}
& U_{2}=\left(\begin{array}{llll}
1 & 0 & 0 & \\
1 & 1 & 0 & \\
0 & 0 & 1 & \\
& & & \\
& & & \\
& & & 1
\end{array}\right),
\end{aligned}
$$

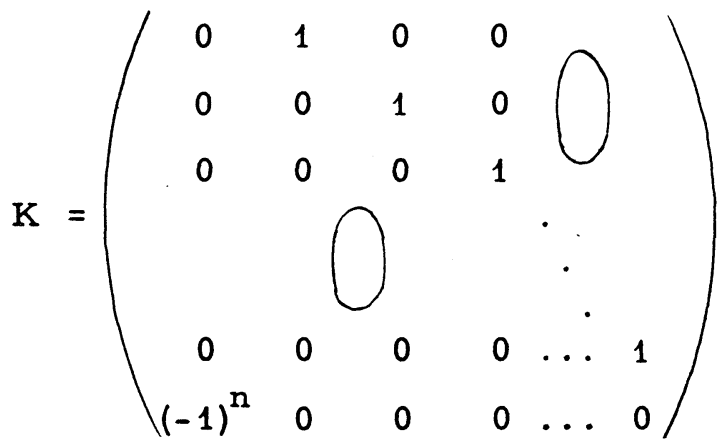

(Trott uses the symbol $U$ instead of $K$, but this could be confused with Neumann's $U$, which is different) are "simpler" than Neumann's; but Neumann gave a set of defining relations using $R$ and $S$, whereas Trott did not.

In terms of the generators

$$
R_{1}=U_{1}=U_{4}=\left(\begin{array}{ll}
0 & 1 \\
1 & 0
\end{array}\right) \text { and } U_{2}=\left(\begin{array}{ll}
1 & 0 \\
0 & 1
\end{array}\right), \quad \operatorname{Trott}[3, \text { p. 252] }
$$


obtained, for $M_{2}$, the defining relations

(1) $R_{1}^{2}=\left(U_{1}^{-1} R_{1} U_{2} R_{1}\right)^{6}=E, \quad U_{2}^{-1} R_{1} U_{2} R_{1} U_{2}^{-1}=R_{1} U_{2} R_{1} U_{2}^{-1} R_{1} U_{2} R_{1}$,

by showing that (1) and

$$
R_{2}=R_{1} U_{2}^{-1} R_{1} U_{2} R_{1}, \quad R=U_{2} R_{2}
$$

are together equivalent to $7.21\left[1\right.$, p. 85] (which define $M_{2}$ ) and

$$
R_{1}=R_{1}, \quad U_{2}=R_{3} R_{2} \text {. }
$$

It should be pointed out that (1) is immediately seen to be equivalent to the relations

$$
\left(R U_{2}\right)^{2}=\left(R^{3} U_{2}^{2}\right)^{2}=\left(R^{2} U_{2}^{2}\right)^{6}=E
$$

which define $M_{2}[1$, p. 88]; in fact (1) is obtained from (2) by letting $\mathrm{R}_{1}=\mathrm{RU}_{2}$.

\section{REFERENCES}

1. H. S. M. Coxeter and W. O. J. Moser, Generators and relations for discrete groups. Springer, Berlin, 1957.

2. B.H. Neumann, Automorphismengruppe der freien Gruppen. Math. Ann. 107(1933) pp. 367-386.

3. S. M. Trott, A pair of generators for the unimodular group. Can. Math. Bull. 5(1962) pp. 245-252.

University of Manitoba 